\title{
SKELETOCHRONOLOGY OF ASIAN GRASS FROG Fejervarya limnocharis (GRAVENHORST, 1829) FROM JAVA TO SUPPORT MANAGEMENT CONSERVATION
}

\author{
Ni Luh Putu Rischa Phadmacanty* ${ }^{1}$, Amir Hamidy $^{1}$ and Gono Semiadi ${ }^{1}$ \\ ${ }^{1}$ Zoology Division (Museum Zoologicum Bogoriense), Research Center for Biology, \\ Indonesian Institute for Sciences, Jl. Raya Jakarta-Bogor Km. 46 Cibinong, Bogor 16911, Indonesia \\ *Corresponding author: rischa_phadmacanty@yahoo.co.id
}

Received: 3 May 2017; Accepted: 23 November 2018

\begin{abstract}
Asian grass frog Fejervarya limnocharis is being utilized as pets, for laboratory experiments, for a mixture of traditional medicine and for cuisine. The harvest of $F$. limnocharis in high volume can threat its population. Biological data such as the age when the specimens are harvested is valuable information to manage the harvesting system in sustainable way. We conducted the skeletochronology technique using paraffin methods and hematoxylin staining from 69 samples (46 males, 21 females, 2 juveniles). The results showed that the age harvested male ranged from 1 to 3 years old, while the female ranged from 2 to 3 years old. The snout-vent length (SVL) of harvested specimens ranges between $39.84-52.37 \mathrm{~mm}$ for both sexes. We propose an intervention in the harvesting system by limitation of the size for harvested specimens to at least $46 \mathrm{~mm}$. In this minimum size, individuals of F. limnocharis have reproduced several times and have contributed to the population in the wild.
\end{abstract}

Keywords: Age determination, Asian grass frog, Fejervarya limnocharis, Java, skeletochronology

\section{INTRODUCTION}

Indonesia is known as one of the world largest exporters of frogs. They are used as pets, for laboratory work (Weldon et al., 2007), traditional medicine (Rowley et al., 2010), and cuisine (Kusrini, 2005; Kusrini \& Alford, 2006a). The export of frogs' legs from Indonesia for consumption is the highest in the world (see Fig. 1), followed by China, Taiwan and Vietnam (Altherr et al., 2011). The largest species being harvested are Fejervarya cancrivora, F. limnocharis (see Fig. 2) and Limnonectes macrodon (Kusrini \& Alford, 2006a).

The Indonesian Scientific Authority recommended the harvest quota for Fejervarya cancrivora legs in 2018 was 80,096,450 individuals. For the F. limnocharis was 700 individuals while for $L$. macrodon is not allowed being harvested due to a significant decrease of wild population (E. Sulistyadi, pers.com. 2018). In the case of F. limnocharis the real harvest of wild population are much higher than the recommendation (Kusrini, 2005). The value of frogs' legs exported in 2014 reached US \$ 22,571,282 (Kemenperin, 2018).

Although under the International Union for Conservation of Nature (IUCN) red list data, the species is listed as the least concern, high exploitation might decrease its natural population and therefore may threaten the existence of the species (Kusrini \& Alford, 2006a). Thus, conservation management is needed to protect this species from extinction.

Age status related to reproductive conditions of any species being exploited plays a crucial point in balancing the natural ecosystem. There are three common methods used for 

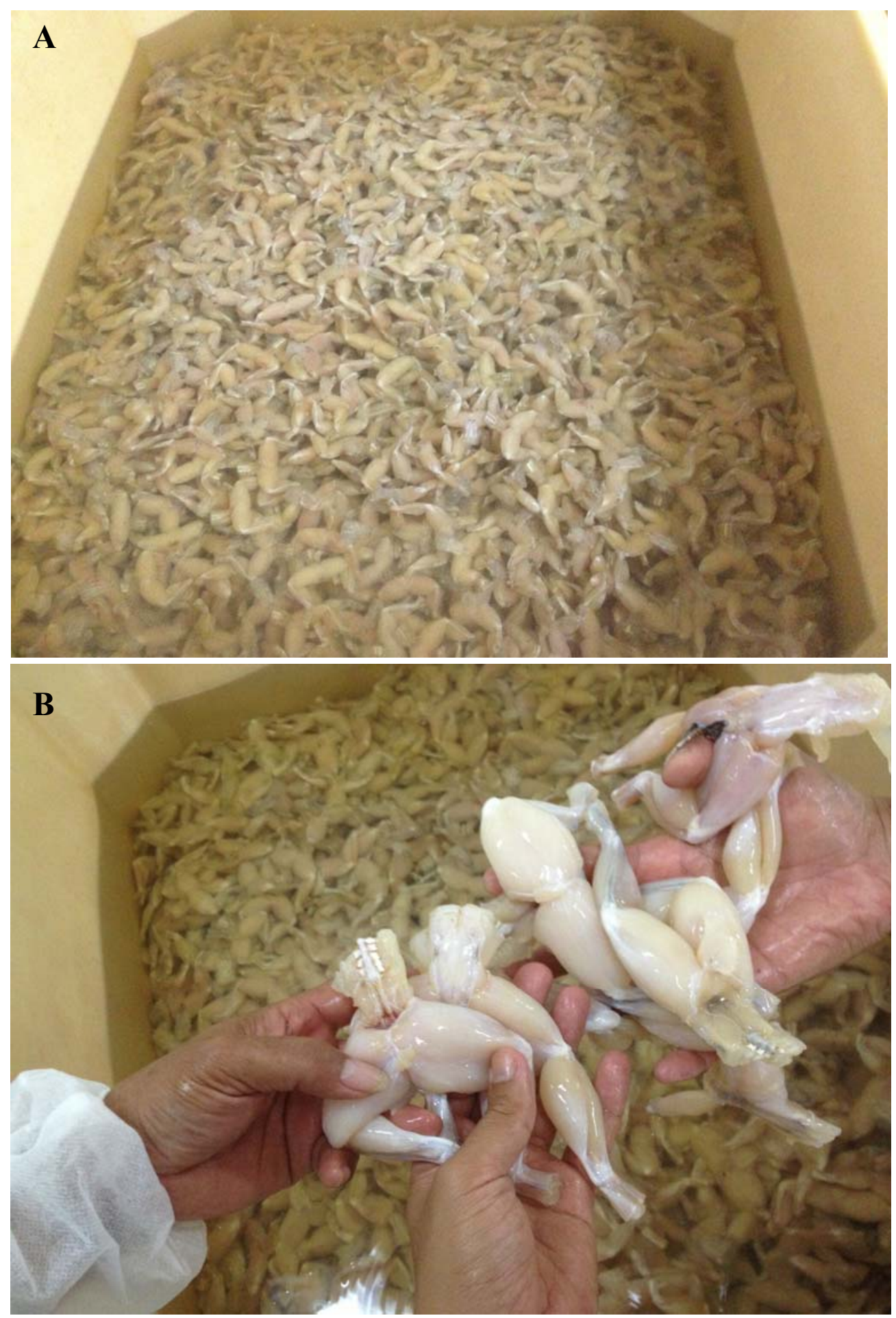

Figure 1. Frog legs: A. for consumption, B. the frog legs are sorted based on the size (Photograph: A. Hamidy). 
age determination i.e. age and body size correlation, mark and recapture, and skeletochronology. Skeletochronology is the most appropriate and accurate method in several species (Eden et al., 2007). This method is based on analyzing the number of lines of arrested growth (LAG) in the cross-section of the frog's bone (Khonsue et al., 2000; Eden et al., 2007). The method has been used to determine the age of several amphibian species in the temperate zone (Guarino et al., 2003), subtropical region (Guarino et al., 1998), and tropical region (Khonsue et al., 2000; Kumbar \& Pancharatna, 2001).

Information regarding age status to body size of Fejervarya limnocharis in Indonesia was unavailable. Therefore it is important to have this data to support the management of the conservation program in Indonesia.

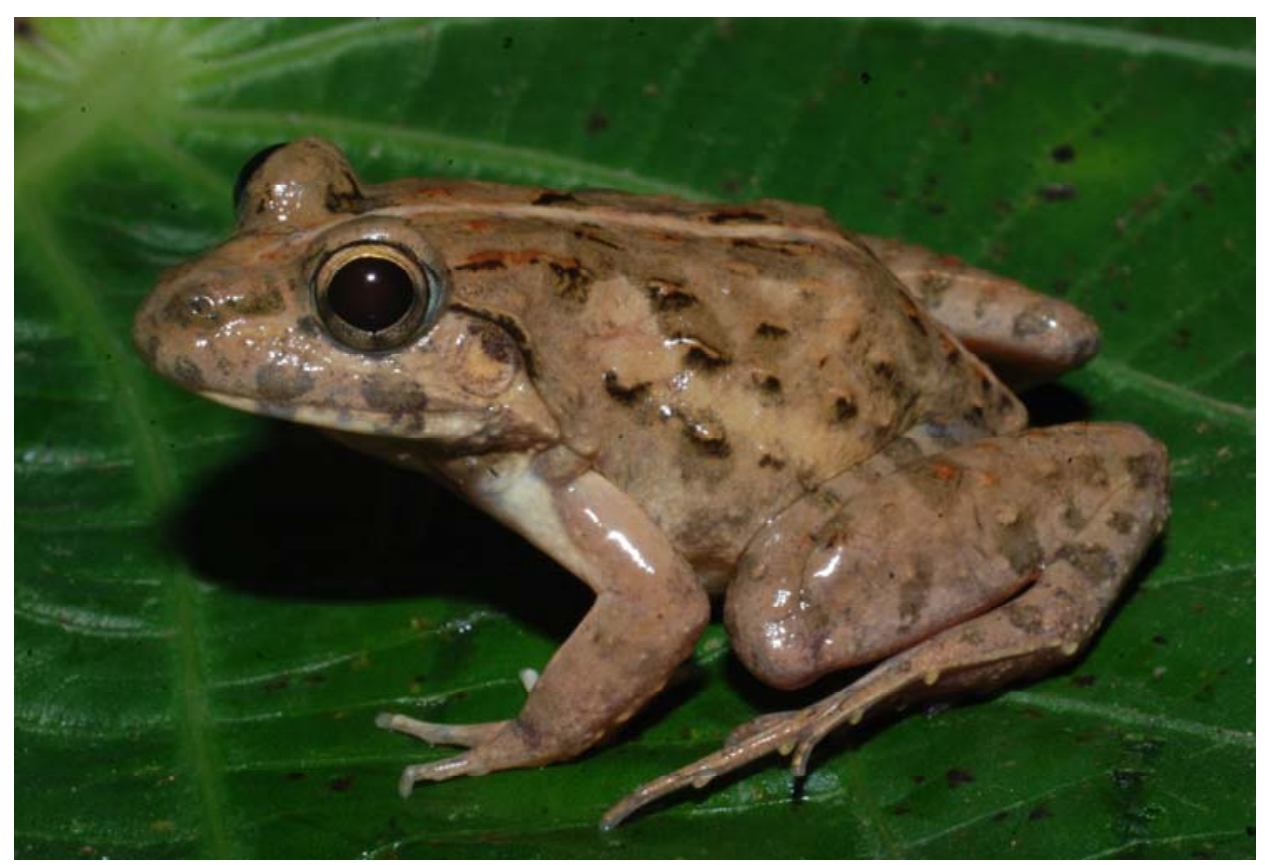

Figure 2. Life specimen of Fejervarya limnocharis (Photograph: A. Hamidy). 


\section{MATERIALS AND METHODS}

\section{Sampling method}

The specimens were obtained from the Dramaga village, Bogor, West Java. Frogs were collected in a paddy field in December 20-23, 2013, in the middle of the wet season, coinciding with the annual peak of reproductive activity of this species. Sampling was performed using encounter visual survey. We collected 69 alive individuals (46 males, 21 females, 2 juveniles) of Fejervarya limnocharis and preserved them in $96 \%$ ethanol. For each specimen, sex, total snout-vent length (SVL) to nearest $\mathrm{mm}$ were analyzed using a digital caliper (Mitutoyo, Japan). All samples were cut at the third phalanges of the third finger and fixed in the $70 \%$ ethanol for skeletochronology.

\section{Skeletochronology}

Skeletochronology processes were carried out according to Liao \& Lu (2010) using the paraffin method. The modification was done on the decalcification process, substituting nitric acid to formic acid. The samples were washed in running tap water overnight and then were decalcified in $10 \%$ of formic acid for eight hours. Later, samples were rinsed in running tap water overnight, followed by staining in hematoxylin for 75 minutes, and then washed in tap water for 30 minutes. The samples were dehydrated in serial ethanol concentrations $(70,80$, $90 \%$, absolute, respectively), each for 1 hour and were cleared in xylene for an hour and were infiltrated in liquid paraffin for 75 minutes. The samples were embedded in paraffin and hardened in room temperature and sectioned in 15 um thickness with a rotary microtome (Yamato RV-240). Samples were deparaffinized and mounted by enthelan and then were observed under a compound microscope at 200x magnification (Nikon Optiphot 2, Japan) attached to a computer for picture analysis. Age was determined by counting the number of lines in the phalangeal bone, where a single LAG was considered as one year old.

\section{RESULTS}

The histological performance of Fejervarya limnocharis in this study showed distinct faint lines in the bone which can be used to estimate the age of the individual (Fig. 3B-D). However, discontinued patterns of LAG from several samples were noticed, presumably because their habitat changes from the wet rice field to dry field (Fig. 3B-D).

Of the 69 samples being analyzed, the distribution age of harvested individuals showed a dominance $(66 \%)$ in the age of two years old and followed by the age of three. The SVL measurement was slightly larger in female than in the male, with the range of SVL size wider in both sexes as they aged (Fig. 4). Wider variation was prominent from the samples of 4 and 5 years old.

There was a tendency of linear relation between the increases of SVL to the number of LAG in both sexes (Figs. $4 \& 5$ ), though the correlation was considered low in both sexes and 

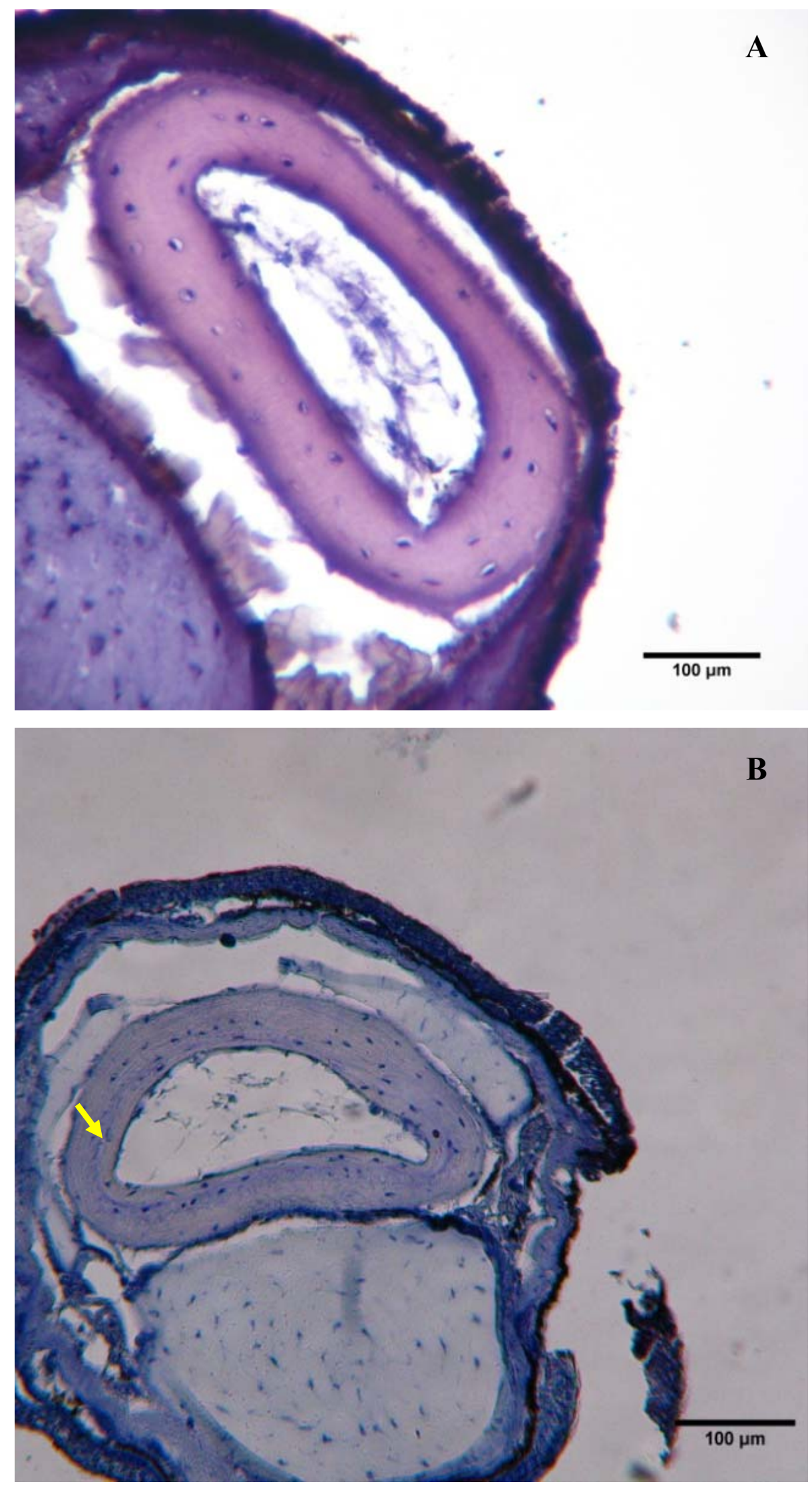

Figure 3. Histology of adult Fejervarya limnocharis phalanges: A. No LAG, B. 1 LAG (arrow). 


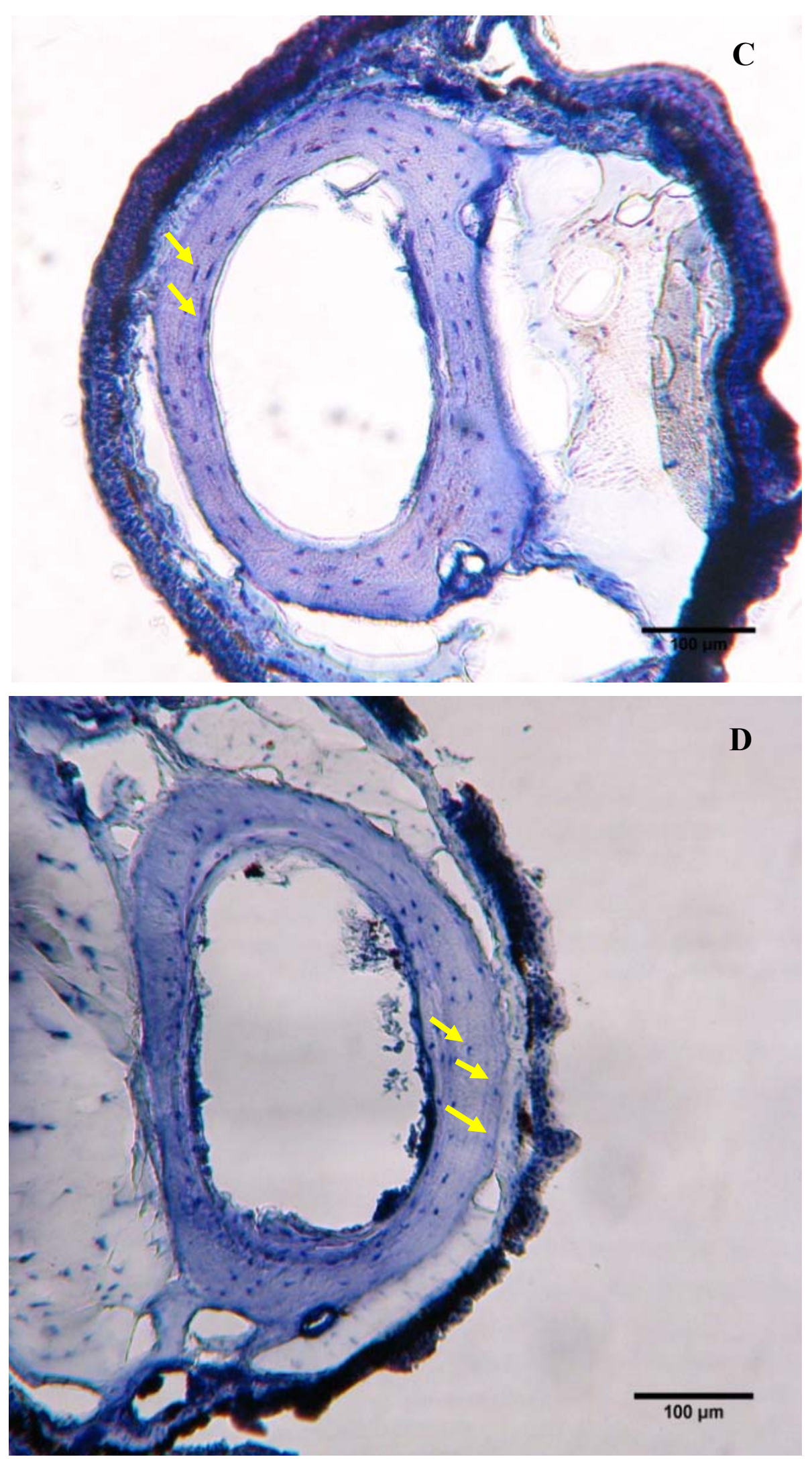

Figure 3. Histology of adult Fejervarya limnocharis phalanges: C. 2 LAGs (arrows), D. 3 LAGs (arrows). 


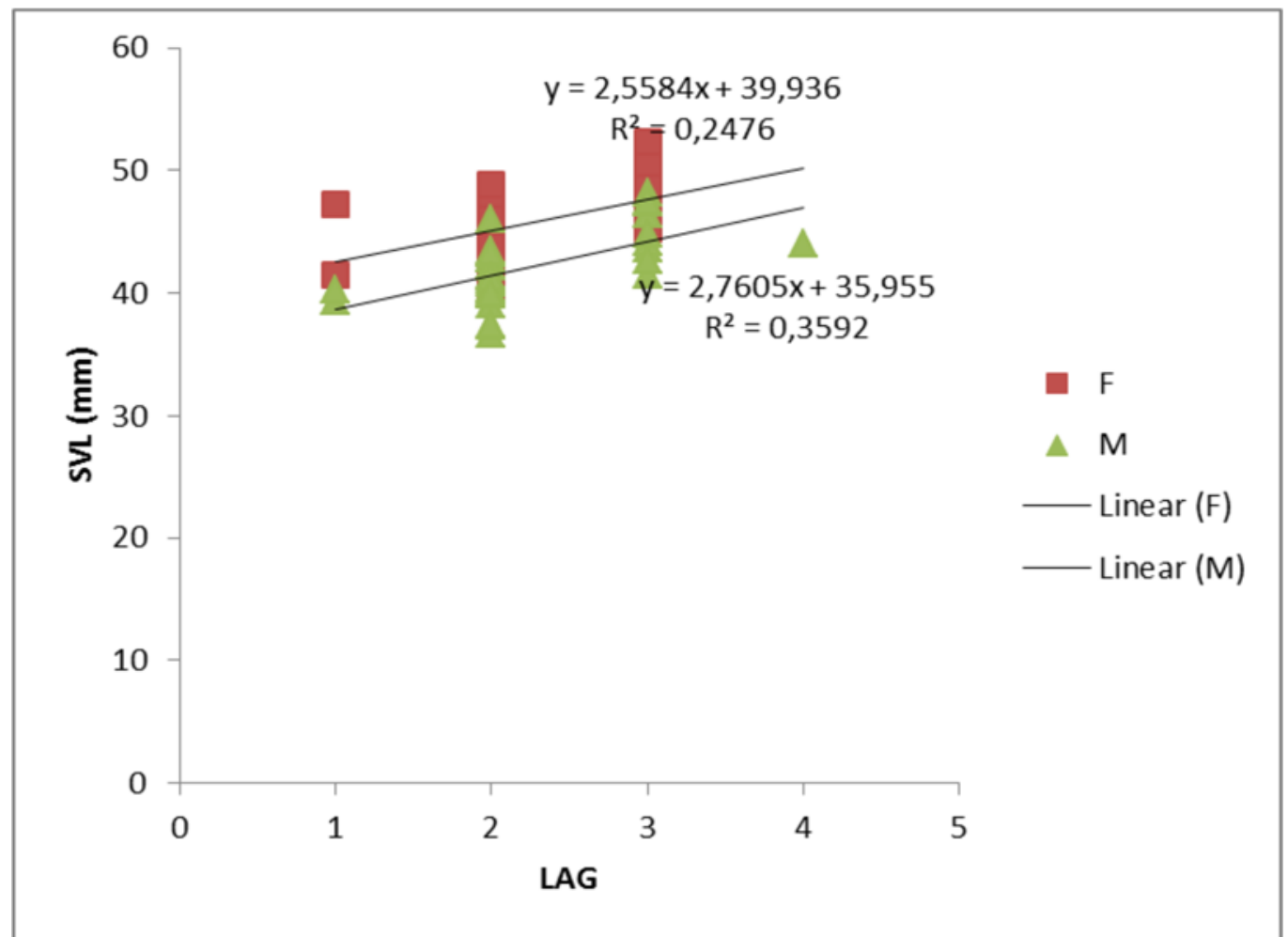

Figure 4. Growth curve of male and female Fejervarya limnocharis (two samples from the juvenile group were dropped from the analysis).

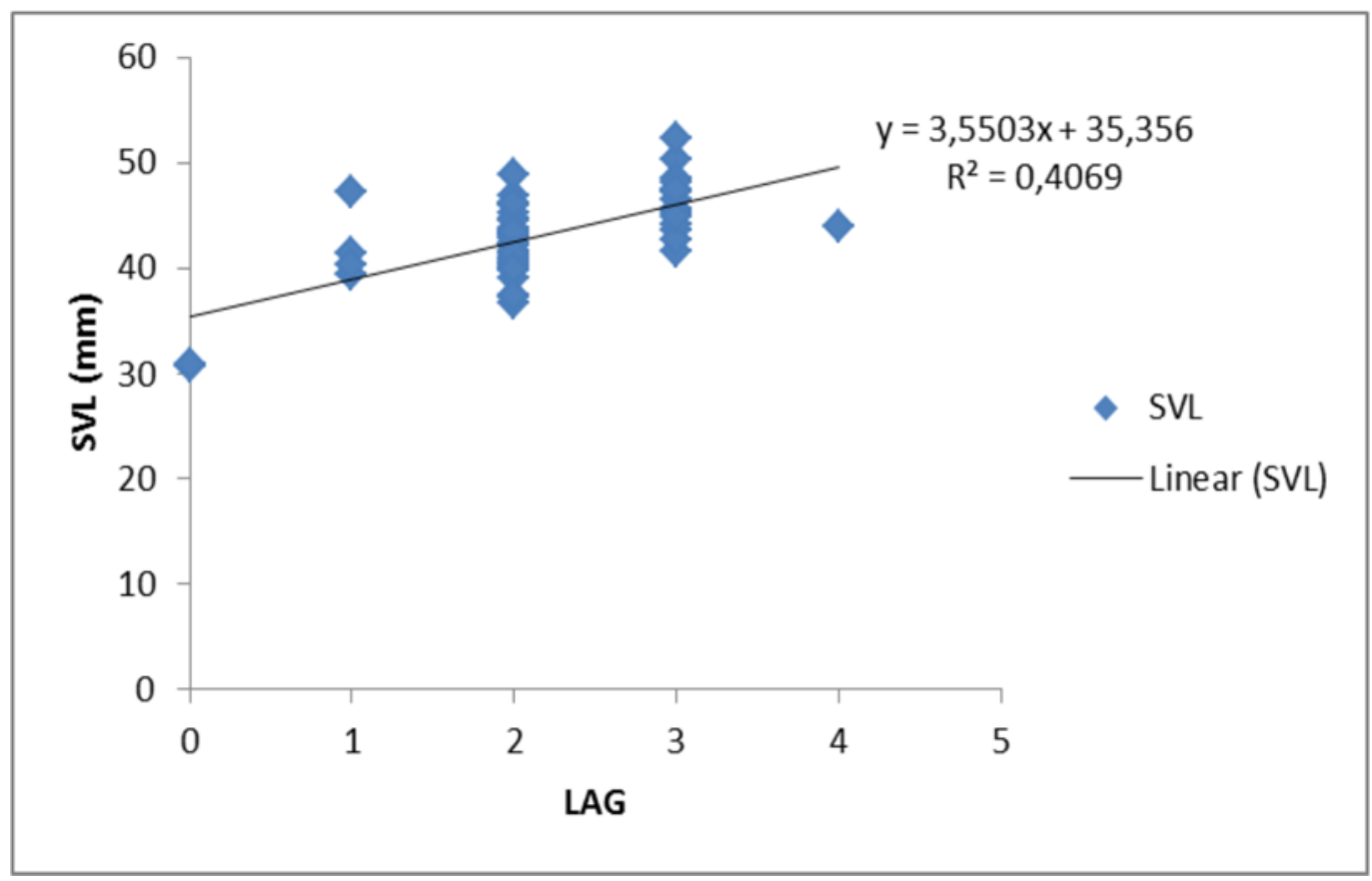

Figure 5. Overall growth curve of Fejervarya limnocharis. 
when it was combined. Sexual maturity in males was detected at one year old, based on the visibility of vocal sac, and in the female at two years old by examination of the gonad.

\section{DISCUSSION}

Indonesia is the primary exporter of frogs' legs. In 1992, the export reached 5,600 tonnes and progressively declined to 3,800 tonnes in 2002. The largest harvest area were in the paddy field of Karawang, West Java (Kurniati \& Sulistyadi, 2016). The exported specimens was determined by the size. However, capture for local consumption does not distinguish the body sizes (Kusrini \& Alford, 2006a).

Age determination for skeletochronology can be used to understand the correlation between age and body size. This study showed that the skeletochronology figures of $F$. limnocharis phalanges from Indonesia were reliable but needed to be treated with caution. The finding is similar to Kusrini \& Alford (2006b) for F. limnocharis and F. cancrivora and to Khonsue et al. (2000) for Rana nigrovittata. The formation of line arrested growth (LAG) in the bone is caused by calcium accumulation. The calcium accumulation is influenced by the availability of environmental calcium and the physiological process of each individual. Another factor that influences LAG formation is the annual life activity cycle (hibernating and activating; Eden et al., 2007). Since tropical frogs do not experience hibernating processes in their lifecycle, this has resulted in faint lines in the tropical frog's bone. However, early studies suggested that lines forming in tropical frogs might occur in a dry season when food availability declines so the foraging activity of frogs also decreases (Reagan \& Waide, 1996). Low activity of frogs during the dry season can produce line formation in frog's legs. Genetic factors also support the LAG formation in the bone (Ferderico et al., 2001).

The results showed that the female SVL was larger than male at the same age. Females F. limnocharis grow faster than males (Shou et al., 2005; Liu et al., 2012). The large females breed explosively for extremely prolonged periods, so they will survive in the reproduction cycle (Woolbright, 1983). Geographical variation, climate, pollution, and altitude can also influence the SVL (Thammachoti et al., 2012; Lu et al., 2012).

The relation between age and body size can predict the size of reproductive stages. The current study was concordant with F. limnocharis in India (Pancharatna \& Deshpande, 2003). The dominant LAG numbers in the current study were three, reflecting in age as three years old. Pancharatna \& Deshpandhe (2003) reported that the natural lifespan of F. limnocharis in southern India was only up to 4 years in both sexes, slightly different from the subtropical $F$. limnocharis in China, which had a lifespan of three years old for males and four years old for females (Liao et al., 2011). These differences are attributed to many factors such as habitat or environmental condition. 
Monitoring and management of harvested populations are required to maintain the stability of frog populations in the wild. The maximum SVL of the frog that were commercially harvested in Indonesia was $78 \mathrm{~mm}$, with a maximum lifespan of this species of four years (Kusrini \& Alford, 2006a). In our study, the maximum age was three years with a maximum SVL of $52,37 \mathrm{~mm}$. Based on the current results, it was estimated that the reproductive body size of this species in Indonesia is between $42.46-46.01 \mathrm{~mm}$ or coincides with the age of 2 years.

Taking into account the reproductive age of this species is between 2-4 years (Phancharatna \& Deshpande, 2003), there should be a benchmark of the maximum size the frog can be harvested. For Indonesia, a minimum harvest size of SVL $46 \mathrm{~mm}$ is suggested as a recommendation.

\section{CONCLUSION}

Skeletochronology can be used to estimate the age of Fejervarya limnocharis in the tropical region. To maintain the sustainability of wild population, harvest size can be recommended from $46 \mathrm{~mm}$.

\section{ACKNOWLEDGMENTS}

This research was supported by LIPI CITES Project, the Japan Science and Technology Agency (JST), Kyoto University, Collaboration Hubs for International Research Program (CHIRP) within the framework of the Strategic International Collaborative Research Program (SICORP). We also thank Wildlife Management and Reproduction laboratory staff and Herpetology laboratory staff of Museum Zoologicum Bogoriense for specimen processing. Mrs. Karen Mulyono helped with editing the first draft.

\section{REFERENCES}

Altherr, S., Goyenechea, A. \& Schubert, D.J. 2011. Canapes to extinction: The international trade in frog's legs and its ecological impact. Pro Wildlife, Defenders of Wildlife, and Animal Welfare Institute.

Eden, C.J., Whiteman, H.H., Dubois-Gray, L. \& Wissinger, S.A. 2007. Accuracy assessment of skeletochronology in the Arizona Tiger Salamander (Ambystoma tigrinum nebulosum). Copeia, 2007(2): 471-477.

Marangoni, F., Schaefer, E., Cajade, R. \& Tejedo, M. 2011. Growth-mark formation and chronology of two Neotropical Anuran species. Journal of Herpetology, 43(3): 546-550.

Guarino, F.M., Lunardi, S., Carlomagno, M. \& Mazzoti, S. 2003. A skeletochronological study of growth, longevity and age sexual maturity in a population of Rana latastei Boulenger 1879 (Amphibia, Anura). Journal of Bioscience, 28: 775-782.

Guarino, F.M., Andreone, F. \& Angelini, F. 1998. Growth and longevity in Mantidactilus microtympanum, a rainforest anuran from Southern Madagascar. Copeia, 1998: 194-198.

Kemenperin. 2018. Pemantauan Ekspor Sub Kelompok Hasil Industri Paha Kodok Beku. http:// kemenperin.go.id/statistik/trend_hs.php?ekspor=1\&sort=2015\&sub=Paha+Kodok+beku/2 July 2018.

Khonsue, W., Matsui, M. \& Misawa, Y. 2000. Age determination by skeletochronology of Rana nigrovittata a frog from tropical forest of Thailand. Zoological Science, 17: 253-257. 
Kumbar, S.M. \& Pancharatna, K. 2001. Determination of age, longevity and age at reproduction of frog Microhyla ornata by skeletochronology. Journal of Bioscience, 26(2): 265-270.

Kumbar, S.M. \& Pancharatna, K. 2002. Annual growth layers in the phalanges of the Indian Skipper Frog Rana cyanophlyctis (Schn). Copeia, 2002(3): 870-872.

Kurniati, H. \& Sulistyadi, E. 2016. Kepadatan populasi kodok Fejervarya cancrivora di persawahan kabupaten Kerawang, Jawa Barat. Jurnal Biologi Indonesia, 13(1): 71-83.

Kusrini, M.D. 2005. Edible frog harvesting in Indonesia: evaluating its impact and ecological context. Thesis. James Cook University.

Kusrini, M.D. \& Alford, R.A. 2006a. Indonesia's exports of frogs' legs. Traffic Bulletin, 21(1): 13-24.

Kusrini, M.D. \& Alford, R.A. 2006b. The application of skeletochronology to estimate ages of three species of frog in West Java. Indonesia. Herpetological review, 37(4): 423-425.

Liao, W.B. \& Lu, X. 2010. Age and growth of subtropical high-elevation torrent frog Amolops manzorum in Western China. Journal of Herpetology, 44(1): 172-176.

Liao, W.B., Lu, X., Shen, Y.W. \& Hu, J.C. 2011. Age structure and body size of two population of the rice frog Rana limnocharis from different altitudes. Italian Journal of Zoology, 78(2): 215-221.

Liu, W., Liu, Y., Huang, Y., Mi Z. \& Li, C. 2012. Skeletochronological study on age structure of a Chinese Endemic Frog (Rana omeimontis). Asian Herpetological Research, 3(3): 252-257.

Pancharatna, K. \& Deshpandhe, S.A. 2003. Skeletochronolgical data on age, body size and mass in the Indian Cricket Frog Limnonectes limnocharis (Boie, 1835) (Anura: Ranidae). Herpetozoa, 16 (1/2): 41-50.

Reagan, D.P. \& Waide, R.B. 1996. The Food Web of Tropical Rain Forest. Chicago: The University of Chicago: 302 pp.

Rowley, J., Brown, R., Bain, R., Kusrini, M., Inger, R., Stuart, B., Wogan, G., Thy, N., Chanard, T., Trung, C.T., Diesmos, A., Iskandar, D.T., Lau, M., Ming, L.T., Makchai, S., Truong, N.Q. \& Phimmachak, S. 2010. Impending conservation crisis for Southeast Asian amphibians. Biology Letters, 6: 336-338.

Shou, L., Du, W.G. \& Shu, L. 2005. Sexual dimorphism and fecundity in the gold stripe pond frog (Pelophylax plancyi) and the terrestrial from Fejervarya limnocharis. Acta Ecologica Sinica, 25 (4): 664-668.

Thammachoti, P., Khonsue, W., Kitana, J., Varanusupakul, P. \& Kitana. N. 2012. Morphometric and gravimetric parameters of the rice frog Fejervarya limnocharis living in areas with different agricultural activity. Journal of Environmental Protection, 2012 (3): 1403-1408.

Weldon, C., De Villiers, A.L. \& du Preez, L.H. 2007. Quantification of the trade in Xenopus laevis from South Africa, with imlpications for biodiversity conservation. African Journal of Herpetology, 56: 77-83.

Woolbright, L.L. 1983. Sexual selection and size dimorphism in anuran amphibia. The American Naturalist, 121(1): 110-119. 